http://dx.doi.org/10.32929/2446-8355.2020v29n1p11-21

\title{
CARACTERÍSTICAS AGRONÔMICAS DO ALGODÃO SUBMETIDO A ÉPOCAS E DOSES DE APLICAÇÃO DE FÓSFORO NO CERRADO PIAUIENSE
}

\author{
Francisco Fernandes Pereira ${ }^{1}$, Rafael Felippe Ratke ${ }^{2 *}$, Alan Mario Zuffo ${ }^{3}$, Wvisvaldo Pereira \\ de Sousa ${ }^{4}$, Fernandes Antônio de Almeida ${ }^{5}$, Fabiano André Petter ${ }^{6}$ \\ ${ }^{1}$ Docente, Entomologia, Universidade Federal do Piauí (UFPI), Bom Jesus, PI. \\ ${ }^{2}$ Docente, Fertilidade do solo, Universidade Federal de Mato Grosso do Sul (UFMS), Chapadão do Sul, MS. *E- \\ mail do autor correspondente: rfratke@gmail.com \\ ${ }^{3}$ Docente, Fitotecnia, Universidade Federal de Mato Grosso do Sul (UFMS), Chapadão do Sul, MS. \\ ${ }^{4}$ Engenheiro agrônomo, Fitotecnia, Universidade Federal do Piauí (UFPI), Bom Jesus, PI. \\ ${ }^{5}$ Docente, Fitopatologia, Universidade Federal de Campina Grande (UFCG), Campina Grande, PB. \\ ${ }^{6}$ Docente, Fitotecnia, Universidade Federal de Mato Groso (UFMT), Sinop, MT.
}

\section{Recebido: 16/05/2019; Aceito: 09/01/2020}

RESUMO: Objetivou-se avaliar a eficiência de doses e épocas de aplicação do fósforo no desenvolvimento e na produtividade do algodão cultivado no Cerrado piauiense e correlacionar as características agronômicas. O delineamento experimental utilizado foi o de blocos casualizados, disposto em esquema fatorial $5 \times 3+1$, com quatro repetições. Os tratamentos foram compostos por cinco doses de fósforo $\left(40,80,120,160\right.$ e $200 \mathrm{~kg} \mathrm{ha}^{-1} \mathrm{de}$ $\left.\mathrm{P}_{2} \mathrm{O}_{5}\right)$ em três épocas $(100 \%$ na semeadura; $50 \%$ na semeadura e $50 \%$ aos 30 dias após a emergência (DAE); 100\% aos 30 DAE), mais o tratamento adicional como controle (sem aplicação: $0 \mathrm{~kg} \mathrm{ha}^{-1}$ de $\mathrm{P}_{2} \mathrm{O}_{5}$ ). As aplicações dos tratamentos foram realizadas manualmente a lanço, sendo a fonte utilizada o superfosfato simples $\left(18 \%\right.$ de $\left.\mathrm{P}_{2} \mathrm{O}_{5}\right)$. Aos 90 DAE foram avaliadas a altura das plantas, o índice relativo de clorofila total, o número de ramos e capulhos, a área foliar, a fitomassa seca ramos, do caule e dos capulhos. Determinou-se também a produtividade do algodão, a máxima eficiência técnica (MET) e a máxima eficiência econômica (MEE). A produção de algodão em caroço foi influenciada pelas doses de $\mathrm{P}$ aplicados na semeadura. A dose de 76,7 $\mathrm{kg} \mathrm{ha}^{-1}$ e de 73,25 $\mathrm{kg} \mathrm{ha}^{-1} \mathrm{de}^{\mathrm{P}} \mathrm{O}_{5}$ proporcionam a MET e MEE, respectivamente para a produção de algodão no Cerrado piauiense. A produtividade de pluma de algodão em caroço está correlacionada com o número de capulhos por planta.

Palavras-chave: Adubação. Capulhos. Gossypium hirsutum.

\section{AGRONOMIC CHARACTERISTICS OF THE COTTON SUBMITTED TO TIMES AND DOSES OF PHOSPHORUS APPLICATION IN THE PIAUÍ CERRADO}

\begin{abstract}
The objective of this study was to evaluate the efficiency of doses and times of application of phosphorus in the development and productivity of cotton cultivated in the Cerrado of Piauí and to correlate the agronomic characteristics. The experimental design was a randomized block design, arranged in a $5 \times 3+1$ factorial scheme, with four replications. The treatments were composed of five doses of phosphorus (40,80,120, 160 and $200 \mathrm{~kg} \mathrm{ha}^{-1}$ of $\left.\mathrm{P}_{2} \mathrm{O}_{5}\right)$ in three seasons $(100 \%$ at sowing, $50 \%$ at sowing and $50 \%$ at 30 days after
\end{abstract}


emergence), $100 \%$ at $30 \mathrm{DAE}$ ), plus additional treatment as a control (without application: 0 $\mathrm{kg} \mathrm{ha}^{-1}$ of $\mathrm{P}_{2} \mathrm{O}_{5}$ ). The applications of the treatments were performed by hand, and the source used was superphosphate $\left(18 \%\right.$ de $\left.\mathrm{P}_{2} \mathrm{O}_{5}\right)$. At 90 DAE was evaluated the height of the plants, the relative index of total chlorophyll, the number of branches and buds, the leaf area, the dry mass branches, the stem, and the bolls. Cotton productivity, maximum technical efficiency (MET) and maximum economic efficiency (MEE) were also determined. The production of cotton seed was influenced by the doses of $\mathrm{P}$ applied in the planting. The dose of $76.7 \mathrm{~kg} \mathrm{ha}^{-1}$ and $73.25 \mathrm{~kg} \mathrm{ha}^{-1}$ of $\mathrm{P}_{2} \mathrm{O}_{5}$ provide the MET and MEE, respectively for cotton production in the Cerrado piauiense. The productivity of cotton seedlings is correlated with the number of bolls per plant.

Key words: Fertilization. Bolls. Gossypium hirsutum.

\section{INTRODUÇÃO}

O algodão (Gossypium hirsutum) é uma importante fibra natural para a indústria têxtil no mundo (WANG et al., 2018). O Brasil destaca-se no agronegócio do algodão sendo o $5^{\circ}$ maior produtor mundial e $8^{\circ}$ maior consumidor, sendo que a área ocupada pela cultura no ano agrícola 2017/18 foi aproximadamente de 1,2 milhões de hectares (COMPANHIA NACIONAL DE ABASTECIMENTO - CONAB, 2017). No Piauí, aproximadamente 7,2 mil hectares da área foram semeados com algodão, sendo localizado no Cerrados piauiense.

Os solos de cerrado caracterizam-se por serem naturalmente pobres em fósforo $(\mathrm{P})$, o que pode reduzira produtividade do algodão (AQUINO et al., 2011). O P solúvel aplicado via adubação de fundação é rapidamente fixado por óxidos e hidróxidos de ferro $(\mathrm{Fe})$ e alumínio (Al), formando complexos de baixa solubilidade. A capacidade do algodão em recuperar $\mathrm{P}$ de fontes pouco solúvel é considerada baixa, sendo esse fato atribuído a pouca eficiência do algodoeiro em absorver e utilizar P do solo (WANG; SHEN; LIAO, 2010).

De todo o fósforo aplicado ao solo, via adubação, a planta só aproveita de 15 a $25 \%$, sendo o restante fixado as partículas minerais do solo, principalmente em solo ácido (AQUINO et al., 2014). Dessa forma, o parcelamento da adubação de P na cultura do algodão pode ser uma alternativa para diminuir a fixação de fósforo no solo, pois diminui o contato de $\mathrm{P}$ as partículas coloidais do solo. $\mathrm{O}$ parcelamento das adubações fosfatadas aumentou o conteúdo de $\mathrm{P}$ disponível no solo 80 dias após a semeadura na cultura do algodão (SANTOS et al., 2012).

As recomendações de doses de $\mathrm{P}$ no solo são baseadas na disponibilidade do mesmo no solo através de análise química do solo (SOUSA; LOBATO, 2004). Quando isso, não é possível, verifica-se a necessidade de doses de $\mathrm{P}$ em função da exportação de $\mathrm{P}$ pela cultura. Assim, necessita-se da calibração de doses em função dos parâmetros produtivos de algodoeiro para solos com características Físico-Químicas como dessa região. Santos et al. (2012) relataram que doses de 100 a $120 \mathrm{~kg} \mathrm{ha}^{-1}$ de $\mathrm{P}_{2} \mathrm{O}_{5}$ são recorrentemente aplicadas no solo com teores altos de $\mathrm{P}$ para o cultivo do algodão no Cerrado, sendo que doses de $75 \mathrm{~kg} \mathrm{ha}^{-}$ ${ }^{1}$ de $\mathrm{P}_{2} \mathrm{O}_{5}$ solúvel poderiam alcançar a produtividade máxima dessa cultura. A dose correta de 
$\mathrm{P}$ pode evitar o desperdício de fertilizante e promover o uso sustentável de $\mathrm{P}$ no sistema produtivo (AMIN et al., 2017).

Monteiro et al. (2005) descrevem que a formação do dossel da planta é inerente a fatores como o cultivar, o clima, a fertilidade do solo e o sistema de cultivo e de colheita. Nesse sentido, o P participada de diversas funções nas plantas e influência o seu desenvolvimento morfofisiológico do algodoeiro. Dessa forma, avaliando-se as características da clorofila, área foliar, massa seca de planta e, correlacionar entre si, poderá indicar o potencial produtivo da cultura.

$\mathrm{O}$ algodoeiro absorve em média $12 \mathrm{~kg} \mathrm{ha}^{-1}$ de $\mathrm{P}$ por tonelada de algodão em caroço produzido, dos quais aproximadamente a metade é exportada na pluma e na semente (CARVALHO; FERREIRA; STAUT, 2007). O pico diário de absorção de $\mathrm{P}$ até a metade do florescimento varia de 0,17 a $0,72 \mathrm{~kg} \mathrm{ha}^{-1} \mathrm{dia}^{-1}$ de P e, cerca de 21 a $36 \%$ do total absorvido é acumulado durante as duas primeiras semanas do florescimento (FURLANI JÚNIOR et al., 2001).

A promoção de maior produtividade das culturas através do manejo da adubação é uma estratégia para assegurar um sistema produtivo sustentável (MEISNER; ROSENHEIM, 2014). Atualmente há a necessidade de pesquisas que subsidiem os produtores do Cerrado piauiense e pesquisas futuras quanto à fertilização fosfatada para a cultura do algodoeiro, uma vez que o Estado do Piauí ainda não apresenta, por parte de órgãos de pesquisa, uma recomendação técnica ou uma aproximação para o uso de fertilizantes para essa cultura. Assim, objetivou-se avaliar a eficiência de doses e épocas de aplicação do fósforo no desenvolvimento e na produtividade do algodão cultivado no Cerrado piauiense e correlacionar as características agronômicas.

\section{MATERIAL E MÉTODOS}

\section{Localização do experimento}

O experimento foi realizado em uma fazenda localizada na Serra da Laranjeira município de Currais - PI ( $09^{\circ} 37^{\prime} 27^{\prime}$ ' S; 44 40'52” WO e altitude média de $541 \mathrm{~m}$ ), no ano agrícola de 2012/2013. O clima da região é do tipo Aw, segundo a classificação climática global de Köppen, com duas estações bem definidas, sendo uma seca, que vai de maio a setembro, e outra chuvosa, que vai de outubro a abril (CAVALCANTE et al., 2011). Os dados de precipitação acumulada e temperatura média durante a realização do experimento encontram-se na Figura 1. 


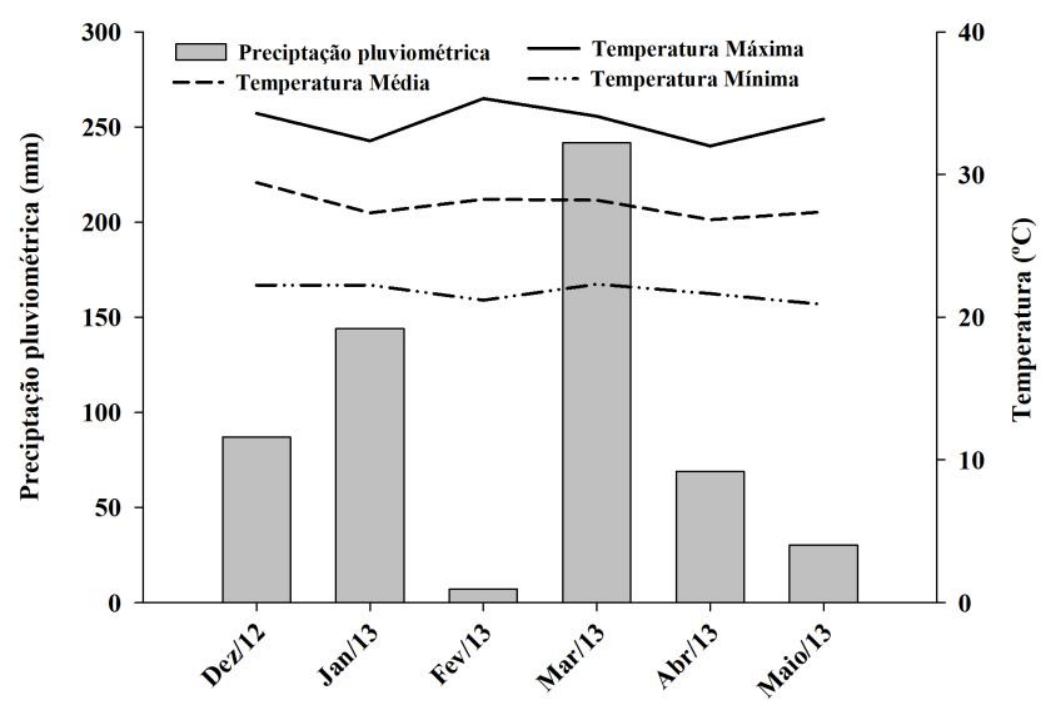

Figura 1. Médias mensais de precipitação pluvial, ocorridas em Currais - PI ano agrícola 2012/13, durante o ciclo do algodão. Monthly averages of rainfall, occurring in Currais - PI agricultural year 2012/13, during the cotton cycle.

Fonte: Instituto Nacional de Meteorologia (INMET, 2018). National Institute of Meteorology (INMET, 2018).

\section{Condução do experimento}

Utilizou-se o delineamento experimental em blocos casualizados, disposto em esquema fatorial $5 \times 3+1$, com quatro repetições. Cada unidade experimental foi constituída por 5,0 m de comprimento com 5,64 m de largura, sendo que, para as avaliações foram consideradas as duas linhas centrais excluindo-se $1 \mathrm{~m}$ em cada extremidade. Os tratamentos foram compostos por cinco doses de fósforo $\left(40,80,120,160\right.$ e $200 \mathrm{~kg} \mathrm{ha}^{-1}$ de $\left.\mathrm{P}_{2} \mathrm{O}_{5}\right)$ em três épocas $(100 \%$ na semeadura; $50 \%$ na semeadura e $50 \%$ aos 30 dias após a emergência (DAE); $100 \%$ aos 30 DAE), mais o tratamento adicional como controle (sem aplicação: $0 \mathrm{~kg} \mathrm{ha}^{-1}$ de $\mathrm{P}_{2} \mathrm{O}_{5}$ ). As aplicações dos tratamentos foram realizadas manualmente a lanço, utilizando como fonte de $\mathrm{P}$ o fertilizante superfosfato simples $\left(18 \%\right.$ de $\left.\mathrm{P}_{2} \mathrm{O}_{5}\right)$.

O solo da área experimental é classificado como LATOSSOLO AMARELO Distrófico típico (PRAGANA et al., 2012). Antes de iniciar o experimento, o solo foi amostrado na camada 0-0,20 $\mathrm{m}$ e as principais propriedadeas químicas (Tabela 1) e textural, utilizando a metodologia de Silva (2011). A análise textural apresentou os seguintes resultados: $216 \mathrm{~g} \mathrm{~kg}^{-1}$ de argila, $24 \mathrm{~g} \mathrm{~kg}^{-1}$ de silte e $760 \mathrm{~g} \mathrm{~kg}^{-1}$ de areia.

Tabela 1. Principais propriedades químicas do solo utilizado nos experimentos. Principal chemical properties of the soil used in the experiments.

\begin{tabular}{|c|c|c|c|c|c|c|c|c|c|}
\hline $\mathrm{pH}$ & $\mathrm{MO}^{1}$ & $\mathrm{P}_{\text {Mehlich-1 }}$ & $\mathrm{H}+\mathrm{Al}$ & $\mathrm{Al}^{3+}$ & $\mathrm{Ca}^{2+}$ & $\mathrm{Mg}^{2+}$ & $\mathrm{K}^{+}$ & $\mathrm{CTC}^{2}$ & $\mathrm{~V}^{3}$ \\
\hline $\mathrm{H}_{2} \mathrm{O}$ & $\mathrm{g} \mathrm{kg}^{-1}$ & $\mathrm{mg} \mathrm{dm}^{-3}$ & -- & - & $-\mathrm{cmol}$ & $\mathrm{m}^{-3}$ & ---- & ---- & $\%$ \\
\hline 4,6 & 15 & 53 & 3,5 & 0,2 & 2,1 & 1,0 & 74 & 6,39 & 51,49 \\
\hline
\end{tabular}

${ }^{1} \mathrm{MO}$ : Matéria orgânica; ${ }^{2} \mathrm{CTC}$ : Capacidade de troca de cations à pH 7,$0 ;{ }^{3} \mathrm{~V}$ : Saturação de bases. Note: ${ }^{1} M O$ : Organic matter; ${ }^{2} \mathrm{CTC}$ : Cations exchange capacity at $\mathrm{pH} 7.0 ;{ }^{3} \mathrm{~V}$ : Base Saturation. 
A semeadura do algodão foi realizada mecanicamente no dia 20 de dezembro de 2013 a uma profundidade de $3 \mathrm{~cm}$ em sistema de semeadura direto, utilizando-se a cultivar FiberMax 993 de ciclo precoce (160 a 190 dias), na densidade de 106 mil sementes por hectare, previamente tratadas com inseticida: Imidacloprido e Tiodicarbe; fungicida: Carbendazim e Thiram nas doses de $360 \mathrm{~g}, 1040 \mathrm{~g} 90 \mathrm{~g}$ e $210 \mathrm{~g}$ de i.a (ingrediente ativo). respectivamente por $100 \mathrm{~kg}$ de sementes.

A adubação de semeadura foi de $25 \mathrm{~kg} \mathrm{ha}^{-1}$ de $\mathrm{N}$ e $50 \mathrm{~kg} \mathrm{ha}^{-1}$ de $\mathrm{K}_{2} \mathrm{O}$ aplicados a $8 \mathrm{~cm}$ abaixo e ao lado das sementes. Já adubação em cobertura foi parcelada em duas vezes, $100 \mathrm{~kg}$ $\mathrm{ha}^{-1} \mathrm{~N}$ e $50 \mathrm{~kg} \mathrm{ha}^{-1} \mathrm{~K}_{2} \mathrm{O}$ aos 30 e 60 DAE, respectivamente. Utilizou-se como fonte de $\mathrm{N}$ (50\% de $\mathrm{N}$ ) e de $\mathrm{K}_{2} \mathrm{O}$ o cloreto de potássio $\left(60 \%\right.$ de $\left.\mathrm{K}_{2} \mathrm{O}\right)$. As recomendações de adubações para o algodoeiro em condição de cerrado foram de acordo com Sousa e Lobato (2004), excluindo-se a adubação fosfatada. Para o controle de plantas daninhas, pragas e doenças foi realizado conforme a necessidade e recomendação para a cultura.

\section{Variáveis analisadas}

Aos 90 DAE foram avaliadas em cinco plantas por parcela: altura das plantas (ALT) determinada da superfície do solo até à inserção da última folha com auxílio de uma régua milimetrada; índice relativo de clorofila total (IRCT), na quinta folha do ápice para a base utilizando-se o clorofilômetro (clorofilLOG CFL 1030). Posteriormente, coletou-se plantas e separou em folhas, ramos, caule e estrutura reprodutivas (capulhos). Assim realizou-se a contagem de ramos (NRC) e capulhos (NC) por planta. Realizou-se a limpeza das folhas com água destilada, e posteriormente determinou-se a área foliar (AF) com o auxílio de um medidor de área foliar tipo esteira (Li-Cor 3100) por meio das dimensões lineares. Em seguida as folhas, ramos e caules foram acondicionadas em sacos de papel, colocadas para secar em estufa à $65^{\circ} \mathrm{C}$ por 72 horas e, posteriormente, pesadas em balança analítica com precisão de $0,0001 \mathrm{~g}$, determinando assim a fitomassa seca ramos (MSFR) do caule (MSC) e dos capulhos (PC).

A produtividade do algodão (PROD) foi estimada colhendo-se a totalidade das plumas de plantas em $2 \mathrm{~m}$ das 2 fileiras centrais da parcela útil aos 150 DAE. Para estimar a média produtividade $\mathrm{kg} \mathrm{ha}^{-1}$, foram pesados o algodão com caroço das plantas coletadas em balança de precisão $(0,0001 \mathrm{~g})$ e corrigidos a umidade de $13 \%$. Com os dados de produtividade foram realizados a máxima eficiência técnica (MET) e a máxima eficiência econômica (MEE). Para a MET utilizou-se a derivada da equação de regressão polinomial da produtividade de algodão em função de doses de $\mathrm{P}_{2} \mathrm{O}_{5}$. Para a MEE utilizou-se da derivação desta equação utilizando o preço do fertilizante e de algodão em caroço tomados como referência - em reais por $\mathrm{kg}$, cotados no mês de maio de 2018 que foram de R \$ 1,41 por cada $\mathrm{kg}$ de superfosfato simples e de R\$ 2,59 por kg de algodão em caroço (SÃO PAULO, 2018).

\section{Análise estatística}

Os dados foram submetidos à análise de variância, utilizando-se o software estatístico Rbio (BHERING, 2017). As médias dos fatores qualitativos foram comparadas pelo teste de médias de Scott-Knott a 5\% de probabilidade. Para as doses de P foram utilizadas a análise de 
regressão e as equações significativas com os maiores coeficientes de determinação (teste $F, p$ $<0,05)$ foram ajustadas.

Os resultados dos parâmetros morfológicos foram avaliados por rede de correlações de Pearson $(P>0,6)$. A rede de correlação (BHERING, 2017) foi utilizada para expressar graficamente os resultados, nos quais a proximidade entre os nós (traços) são proporcionais aos valores de correlação absoluta entre os parâmetros avaliados. A espessura da borda foi controlada pela estimativa das correlações, onde as correlações positivas foram destacadas em verde, enquanto as correlações negativas foram representadas em vermelho.

\section{RESULTADOS E DISCUSSÃO}

As características agronômicas do algodão não foram influenciadas pelas doses de $\mathrm{P}$, épocas de aplicação e interação (fatorial x adicional). Porém, para a interação (doses de P x épocas), verificou-se influências significativas para a produtividade e o número de capulho (Tabela 2).

Tabela 2. Análise de variância dos parâmetros agronômicos do algodoeiro em função das épocas de aplicação de fósforo no Cerrado piauiense, ano agrícola 2012/2013. Variance analysis of cotton agronomic parameters as a function of phosphorus application time in Cerrado piauiense, agricultural year 2012/2013.

\begin{tabular}{lccccccccc}
\hline \multirow{2}{*}{ Causas de variação } & ICRT $^{1}$ & ALT & MSC & MSF & AF & NR & NC & PC & PROD \\
\cline { 2 - 8 } & ----------------------Valor de F $^{2}$ & PR----------------- \\
\hline Época & $0,73 \mathrm{~ns}$ & $0,80 \mathrm{~ns}$ & $0,90 \mathrm{~ns}$ & $1,17 \mathrm{~ns}$ & $2,09 \mathrm{~ns}$ & $0,04 \mathrm{~ns}$ & $0,14 \mathrm{~ns}$ & $1,50 \mathrm{~ns}$ & $2,63 \mathrm{~ns}$ \\
Doses & $0,41 \mathrm{~ns}$ & $1,13 \mathrm{~ns}$ & $1,59 \mathrm{~ns}$ & $0,70 \mathrm{~ns}$ & $1,31 \mathrm{~ns}$ & $1,23 \mathrm{~ns}$ & $0,78 \mathrm{~ns}$ & $0,64 \mathrm{~ns}$ & $0,92 \mathrm{~ns}$ \\
Época x doses & $0,47 \mathrm{~ns}$ & $0,74 \mathrm{~ns}$ & $0,88 \mathrm{~ns}$ & $0,93 \mathrm{~ns}$ & $1,61 \mathrm{~ns}$ & $1,71 \mathrm{~ns}$ & $2,38^{*}$ & $0,45 \mathrm{~ns}$ & $2,48^{*}$ \\
Adicional x Fatorial & $0,27 \mathrm{~ns}$ & $0,85 \mathrm{~ns}$ & $0,99 \mathrm{~ns}$ & $0,34 \mathrm{~ns}$ & $0,63 \mathrm{~ns}$ & $0,87 \mathrm{~ns}$ & $0,52 \mathrm{~ns}$ & $0,72 \mathrm{~ns}$ & $0,84 \mathrm{~ns}$ \\
\hline $\mathrm{CV}^{3}(\%)$ & 1,76 & 4,28 & 15,56 & 18,34 & 23,77 & 7,60 & 13,80 & 31,49 & 24,85 \\
\hline
\end{tabular}

${ }^{1}$ ICRT - índice de clorofila total; ALT - altura de planta; MSC - massa seca de caule; MSF - massa seca de folhas; AF - área Foliar; NR - número de ramos; NC - número de capulhos; PC - peso capulhos e PROD produtividade de algodão em caroço. ${ }^{2} \mathrm{~ns}$ - não significativo; *significativo pelo teste $\mathrm{F}(\mathrm{P}>0,05)$. ${ }^{3} \mathrm{CV}-$ Coeficiente de variação. ${ }^{I} I C R T$ - total chlorophyll index; ALT - plant height; MSC - stem dry matter; MSF - leaf dry matter; AF - Foliar area; NR - number of branches; NC - number of heads; PC - seedling weight and PROD - seed cotton yield. ${ }^{2} n s$ - not significant; * significant by the F test $(P>0.05) .{ }^{3} \mathrm{CV}$ - Coefficient of variation.

A ausência do efeito das aplicações parceladas de P (Tabela 2 e 3) nas características agronômicas do algodão pode estar relaciona aos teores altos de $\mathrm{P}$ no LATOSSOLO AMARELO Distrófico avaliado (Tabela 1). Portanto, em solo com altos teores de P, independentemente da dose e da época de aplicação não culminará em incremento nas características agronômicas do algodoeiro. Todavia, ao relacionar com as épocas com as doses de $\mathrm{P}$, observou-se efeito significativo isolado para a número de capulhos $\mathrm{e}$ produtividade. $\mathrm{O}$ parcelamento das doses de $\mathrm{P}$ podem culminar em respostas divergentes nas plantas de algodoeiro conforme as condições de solo. Dessa forma, em solos mais arenosos o $\mathrm{P}$ aplicado na semeadura do algodão torna-se mais disponível, devido ter poucos sítios de sorção no solo para promover sua fixação e torná-lo indisponível. Por outro lado, a limitação de P pode imprimir menor resposta produtiva do algodoeiro (SANTOS et al., 2012). 
Tabela 3. Características agronômicas do algodoeiro em função das épocas de aplicação de fósforo no Cerrado piauiense, ano agrícola 2012/2013. Agronomic characteristics of cotton as a function of the phosphorus application times in the Cerrado of Piauí, agricultural year 2012/2013.

\begin{tabular}{|c|c|c|c|c|c|c|c|c|c|c|}
\hline $\begin{array}{l}\text { Época de } \\
\text { Aplicação }\end{array}$ & Dose & $\mathrm{ICRT}^{1}$ & ALT & MSC & MSF & $\mathrm{AF}$ & NR & $\mathrm{NC}$ & $\mathrm{PC}$ & PROD \\
\hline & $\mathrm{kg} \mathrm{ha}^{-1}$ & & $\mathrm{~cm}$ & g planta $^{-1}$ & g planta $^{-1}$ & $\mathrm{~cm}^{2}$ & planta $^{-1}$ & planta $^{-1}$ & mg planta ${ }^{-1}$ & $\mathrm{~kg} \mathrm{ha}^{-1}$ \\
\hline Controle & 0 & 54,58 & 93,44 & 60,25 & 35,00 & 57,31 & 14,25 & 9,10 & 9,22 & 945,52 \\
\hline \multirow{5}{*}{$100 \%$ plantio } & 40 & 56,03 & 85,44 & 60,00 & 39,00 & 63,73 & 12,13 & 8,93 & 8,23 & 1280,63 \\
\hline & 80 & 56,66 & 87,88 & 45,50 & 29,50 & 49,62 & 12,13 & 6,90 & 10,20 & 1156,16 \\
\hline & 120 & 57,08 & 96,63 & 74,50 & 50,50 & 83,08 & 16,00 & 10,20 & 11,64 & 1104,75 \\
\hline & 160 & 56,85 & 88,06 & 47,25 & 34,25 & 59,56 & 14,50 & 8,10 & 14,99 & 1050,64 \\
\hline & 200 & 56,98 & 94,38 & 70,75 & 51,00 & 103,84 & 15,13 & 8,60 & 12,37 & 446,14 \\
\hline Média & & 56,72 & 90,48 & 59,60 & 40,85 & 71,97 & 13,98 & 8,55 & 11,49 & 1007,66 \\
\hline \multirow{5}{*}{$50 / 50$} & 40 & 58,86 & 96,31 & 62,50 & 40,00 & 64,17 & 15,00 & 7,20 & 17,32 & 391,61 \\
\hline & 80 & 55,73 & 93,38 & 68,00 & 55,45 & 69,52 & 13,88 & 9,85 & 12,19 & 733,46 \\
\hline & 120 & 55,71 & 87,94 & 49,00 & 37,50 & 40,88 & 12,50 & 7,05 & 26,13 & 1082,36 \\
\hline & 160 & 57,99 & 92,50 & 47,00 & 35,50 & 52,75 & 14,25 & 9,85 & 15,25 & 844,01 \\
\hline & 200 & 56,18 & 101,06 & 56,00 & 35,00 & 47,37 & 15,25 & 7,10 & 13,03 & 1136,44 \\
\hline Média & & 56,90 & 94,24 & 56,50 & 40,69 & 54,94 & 14,18 & 8,21 & 16,78 & 837,58 \\
\hline \multirow{5}{*}{$\begin{array}{l}100 \% \text { pós } \\
\text { semeadura }\end{array}$} & 40 & 55,43 & 96,63 & 65,50 & 45,51 & 77,17 & 14,50 & 10,92 & 7,61 & 1155,68 \\
\hline & 80 & 54,93 & 88,44 & 64,50 & 44,10 & 45,25 & 14,00 & 6,95 & 18,90 & 937,35 \\
\hline & 120 & 56,27 & 93,25 & 65,50 & 53,50 & 69,63 & 14,25 & 8,20 & 14,18 & 1284,68 \\
\hline & 160 & 56,75 & 89,81 & 51,00 & 41,50 & 56,47 & 12,63 & 8,40 & 11,16 & 1108,88 \\
\hline & 200 & 55,99 & 96,06 & 78,00 & 57,00 & 76,77 & 15,00 & 7,80 & 13,25 & 1060,91 \\
\hline Média & & 55,88 & 92,84 & 64,90 & 48,32 & 65,06 & 14,08 & 8,45 & 13,02 & 1109,50 \\
\hline Média Geral & & 56,43 & 92,55 & 60,08 & 42,55 & 63,57 & 14,08 & 8,44 & 13,55 & 975,80 \\
\hline
\end{tabular}

${ }^{1}$ ICRT - índice de clorofila total; ALT - altura de planta; MSC - massa seca de caule; MSF - massa seca de folhas; AF - área Foliar; NR - número de ramos; NC - número de capulhos; PC - peso capulhos e PROD produtividade de algodão em caroço. ${ }^{I}$ ICRT - total chlorophyll index; ALT - plant height; MSC - stem dry matter; $M S F$ - leaf dry matter; AF - Foliar area; NR - number of branches; NC - number of heads; PC - seedling weight and PROD - seed cotton yield.

A produtividade de algodão apresentou-se valores abaixo da média produtiva $(2.135 \mathrm{~kg}$ $\mathrm{ha}^{-1}$ ) para a região do Piauí (COMPANHIA NACIONAL DE ABASTECIMENTO - CONAB, 2013), tais valores, estão relacionado as condições climáticas, especialmente o regime hídrico cujos valores foram abaixo da média histórica (Figura 1). As restrições hídricas limitaram o desenvolvimento e a produtividade do algodoeiro. Trabalhos demonstram resposta produtiva do algodão a doses de $\mathrm{P}$ em área irrigadas, em função de favorecer a difusão do mesmo no solo (AQUINO et al., 2011). 
Embora houve diferença estatísticas no teste F para o número de capulho (Tabela 2), ao realizar a análise de regressão verificou-se que não houve diferença estatística pelo teste $\mathrm{T}$, bem como, um baixo coeficiente de determinação (Figura 2A). As doses e épocas de aplicação de $\mathrm{P}$ tende a favorecer a produtividade de algodão em caroço, apresentando uma regressão polinomial significativa apenas na época da semeadura (Figura $2 \mathrm{~B}$ ). $\mathrm{O}$ fornecimento de nitrogênio $(\mathrm{N})$ e potássio $(\mathrm{K})$ favorece a absorção de $\mathrm{P}$, e assim adubações de base com $\mathrm{N}$, $\mathrm{P}$ e K na semeadura, aumentam a disponibilidade de P. Assim, verifica-se a necessidade de fornecimento de $\mathrm{P}$ durante a semeadura do algodoeiro.
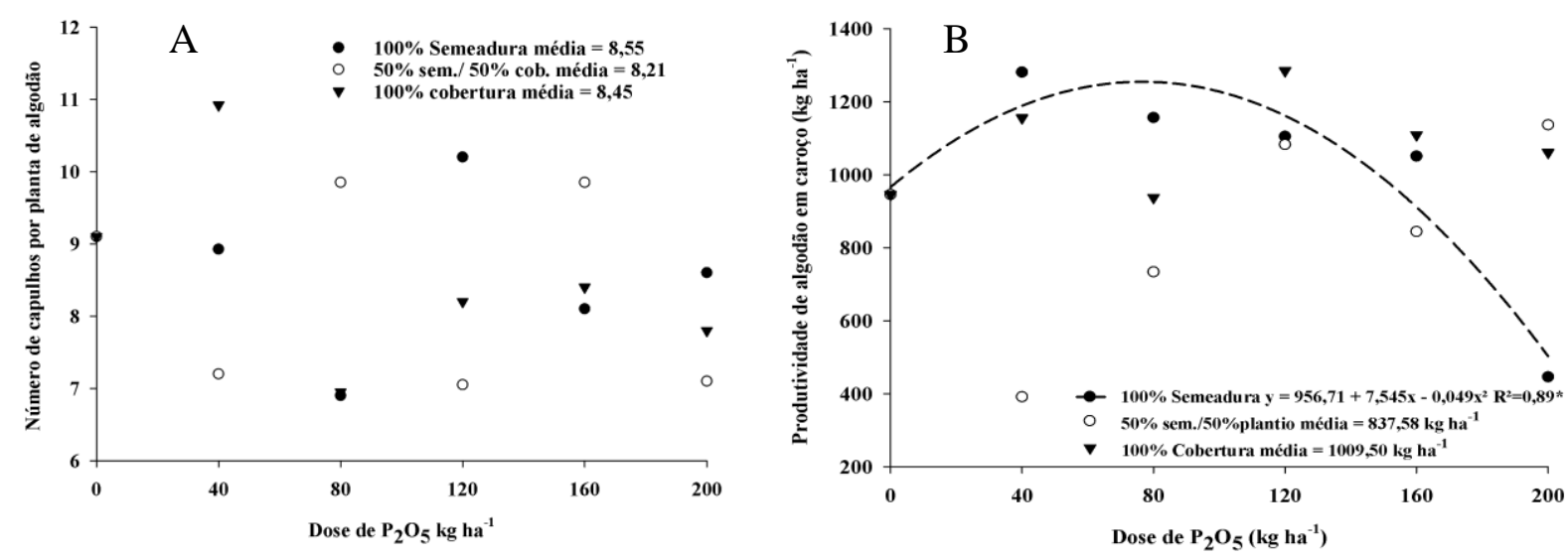

Figura 2. Número de capulho (A) e produtividade (B) de algodão em caroço em função das épocas de aplicação de fósforo no Cerrado piauiense, ano agrícola 2012/2013. *equação de regressão linear significativa pelo teste $\mathrm{F}(\mathrm{P}>0,01)$. Boll number $(A)$ and yield $(B)$ of seed cotton in function of the phosphorus application times in the Cerrado of Piaui, agricultural year 2012/2013. * significant linear regression equation by the $F$ test $(P>0.01)$.

Os níveis de $\mathrm{P}$ no solo do experimento estavam altos para a cultura do algodão (SOUSA; LOBATO, 2004). Em solos com alto teor de $\mathrm{P}$ pode-se parcelar as adubações fosfatadas devido não haver perda de $\mathrm{P}$ por fixação, devido a sua disponibilidade para a planta. Nessa situação, a maior disponibilidade de $\mathrm{P}$ na fase reprodutiva da cultura, que apresenta maior demanda de P nessa fase. Porém, não houve incrementos produtivos com o parcelamento de P. Assim, o parcelamento de $\mathrm{P}$ no solo de cerrado também é dispensável (AQUINO et al., 2014; SANTOS et al., 2012).

A MET foi proporcionada pela dose de $76,47 \mathrm{~kg} \mathrm{ha}^{-1}$ de $\mathrm{P}_{2} \mathrm{O}_{5}$, com a produtividade de $1.254,00 \mathrm{~kg} \mathrm{ha}^{-1}$ de algodão em carroço. A MEE foi proporcionada com a dose de 71,00 $\mathrm{kg} \mathrm{ha} \mathrm{ha}^{-}$ ${ }^{1}$ de $\mathrm{P}_{2} \mathrm{O}_{5}$. Dessa forma, essa dose melhora a eficiência do uso das adubações $\mathrm{P}$ na cultura do algodão para o Cerrado Piauense, devido a escassez de recomendações de adubações para essa região. Doses entre 60 a $75 \mathrm{~kg} \mathrm{ha}^{-1}$ são suficientes para repor a exportação de $\mathrm{P}$ do solo para uma produtividade de algodão em caroço acima de $3.000 \mathrm{~kg} \mathrm{ha}^{-1}$ (SANTOS et al., 2012) $\square$. A baixa mobilidade e a permanência de P no solo no algodão pode atender as necessidades da cultura sucessora (SILVA; AQUINO; BATISTA, 2011).

Os parâmetros de desenvolvimento do algodoeiro influenciam sua produtividade. Porém, verificou-se através da correlação de Pearson que o desenvolvimento do algodoeiro nesse ambiente edafoclimático pouco influenciou sua produtividade (Figura 3). As correlações 
positivas foram encontradas entre os parâmetros de MSFR, MSC, AF e NR, e menor correlação positiva com ALT e IRCT. Mostrando que os aspectos de desenvolvimento do algodão são eficientes em promover a conversão de fotoassimilados em matéria seca. Assim, quanto maior a AF, maior a MS da planta. Monteiro et al., (2005) avaliaram que a área foliar correlaciona com a matéria seca da folha de algodão. Entretanto, observou-se que somente o número de capulhos apresenta correlação positiva para a produtividade de pluma de algodão em caroço.

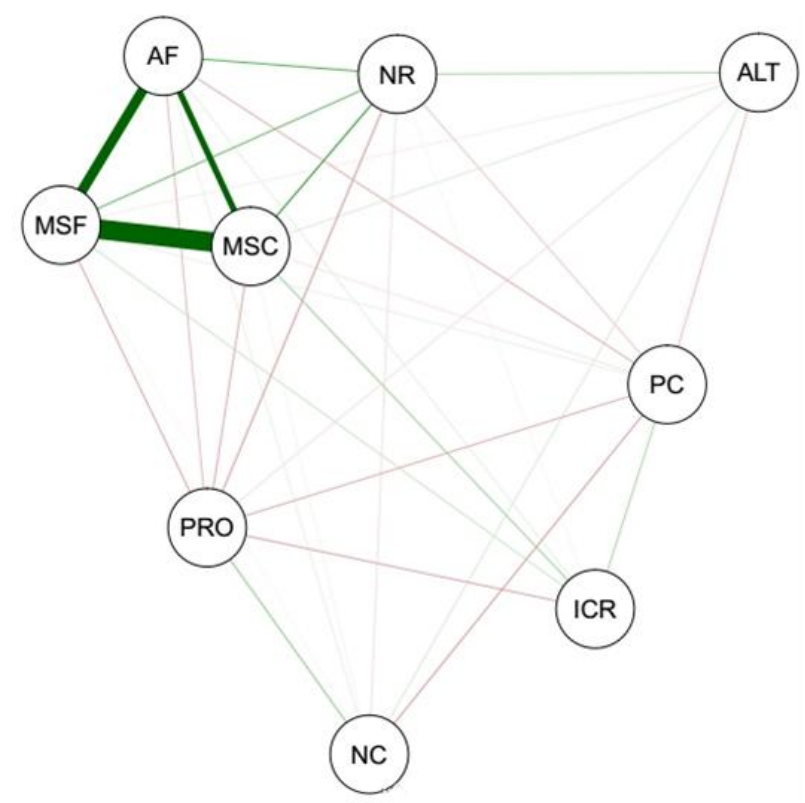

Figura 3. Rede de correlação dos parâmetros: IRCT - Índice de clorofila total; MSC - Massa seca de caule; MSF - Massa seca de folhas; ALT -Altura de planta; AF - Área Foliar; NC Número de Capulhos; PC - Peso capulhos e PROD - Produtividade de algodão em caroço. Correlation network of the parameters: IRCT - Total chlorophyll index; MSC - Dry stem mass; MSF - Dry leaf mass; ALT-Plant height; AF - Foliar area; NC - Number of Barges; PC - Balls weight and PROD - Productivity of cotton in stone.

Dessa forma, a promoção de número de capulhos deve-se ser sustentada para obter melhores produtividade de plumas de algodão em caroço. Porém, devido a mesma ter hábito perene na fase reprodutiva, a manutenção da parte vegetativa nesta fase pode prejudicar a produtividade de plumas. Assim, verifica-se a necessidade do manejo de reguladores de crescimento e desfolhantes para promover maior produtividade do algodoeiro, além da dose de $\mathrm{P}$ correta aplicado na semeadura da cultura.

\section{CONCLUSÃO}

As doses de $\mathrm{P}$ aplicados em diferenças épocas não influenciam a morfologia da planta de algodão em Latossolo com níveis de P elevado. Todavia, a produtividade de caroços de algodão apresenta curva de resposta as doses de $\mathrm{P}$ aplicados na semeadura. Assim, estima-se que a dose de $76,47 \mathrm{~kg} \mathrm{ha}^{-1}$ e de $67,00 \mathrm{~kg} \mathrm{ha}^{-1}$ de $\mathrm{P}_{2} \mathrm{O}_{5}$ proporcionam a MET e MEE, respectivamente para a produção de algodão no Cerrado Piauiense. 
Os parâmetros morfológicos vegetativos da planta de algodoeiro correlacionam entre si. Sendo que a produtividade de pluma de algodão em caroço está correlacionada com o número de capulhos por planta. Dessa forma, deve-se utilizar manejos produtivos que promovam e preservem a manutenção de capulhos.

\section{REFERÊNCIAS BIBLIOGRÁFICAS}

AMIN, A.; NASIM, W.; MUBEEN, M.; NADEEM, M.; ALI, L.; HAMMAD, H. M.; FATHI, Optimizing the phosphorus use in cotton by using CSM-CROPGRO-cotton model for semiarid climate of Vehari-Punjab, Pakistan. Environmental Science and Pollution Research, Heidelberg, v. 24, n. 6, p.5811-5823, 2017. Disponível em: https://doi.org/10.1007/s11356016-8311-8. Acesso em: 2 abr. 2019.

AQUINO, L. A. DE.; BERGER, P. G.; OLIVEIRA, R. A.; NEVES, J. C. L.; BATISTA, C. H. Parcelamento do fertilizante fosfatado no algodoeiro em sistema de cultivo irrigado e de sequeiro. Revista Brasileira de Engenharia Agrícola e Ambiental, Campina Grande, v. 15, n. 5, p.463-470, 2011. Disponível em: https://doi.org/10.1590/s1415-43662011000500005. Acesso em: 10 abr. 2019.

AQUINO, L. A. DE; BERGER, P. G.; NEVES, J. C. L.; AQUINO, R. F. B. A. Acúmulo e exportação de nutrientes pelo algodoeiro com a apliacação parcelada de fósforo. Bioscience Journal, Uberlândia, v. 300, n. supplement 1, p.12-21, 2014. Disponível em: http://www.seer.ufu.br/index.php/biosciencejournal/article/view/13949/14473. Acesso em: 14 abr. 2019.

BHERING, L. L. Rbio: A tool for biometric and statistical analysis using the $\mathrm{R}$ platform Rbio: A tool for biometric and statistical analysis using the R platform SOFTWARE/DEVICE RELEASE. Crop Breeding and Applied Biotechnology, Viçosa, MG, v. 17, n. 17, p.187190, 2017. Disponível em: https://doi.org/10.1590/1984-70332017v17n2s29. Acesso em: 14 abr. 2019.

CARVALHO, M. DA. C.; FERREIRA, G. B.; STAUT, L. A. Nutrição, calagem e adubação do algodoeiro. In: FREIRE, E. (ed.). Algodão no cerrado do Brasil. Brasília: ABRAPA, 2011. cap. 19, p.677-752.

CAVAlCANTE, Í. H. L.; MARTINS, A. B. G.; SILVA JÚNIOR, G. B. DA.; ROCHA, L. F. DA.; NETO, R. F.; CAVALCANTE, L. F. Adubação orgânica e intensidade luminosa no crescimento e desenvolvimento inicial da Pitaya em Bom Jesus-PI. Revista Brasileira de Fruticultura, Jaboticabal, v. 33, n. 3, p.970-983, 2011. Disponível em: https://doi.org/10.1590/s0100-29452011005000086. Acesso em: 10 abr. 2019.

COMPANHIA NACIONAL DE ABASTECIMENTO - CONAB.. Acompanhamento da Safra Piauiense, grãos: boletim parcial da safra 2017/2018. Brasília, DF, 2017. Disponível em: www.conab.gov.br. Acesso em: 12 dez. 2017.

FURLANI JÚNIOR, E.; SILVA, N. M.; BUZETTI, S.; SÁ, M. E.; ROSOLEM, C. A.; CARVALHO, M. A. C. Extração de macronutrientes e crescimento do cultivar de algodão IAC 22. Cultura agronômica, Ilha Solteira, v. 10, n. 1, p.71-87, 2001. Disponível em: 
http://ojs.unesp.br/index.php/rculturaagronomica/issue/viewIssue/69/14. Acesso em: 10 abr. 2019.

MEISNER, M. H.; ROSENHEIM, J. A. Ecoinformatics reveals effects of crop rotational histories on cotton yield. PLoS ONE, Califórnia, v. 9, n. 1, p.1-8, 2014. Disponível em: https://doi.org/10.1371/journal.pone.0085710. Acesso em: 10 abr. 2019.

MONTEIRO, J. E. B. A.; SENTELHAS, P. C.; CHIAVEGATO, E. J.; GUISELINI, C.; SANTIAGO, A. V.; PRELA, A. Estimação da área foliar do algodoeiro por meio de dimensões e massa das folhas. Bragantia, Campinas, v. 64, n. 1, p.15-24, 2005. Disponível em: https://doi.org/10.1590/S0006-87052005000100002. Acesso em: 23 fev. 2019.

PRAGANA, R. B.; RIBEIRO, M. R.; NÓBREGA, J. C. A.; FILHO, M. R. R.; DA COSTA, J. A. Qualidade física de Latossolos Amarelos sob plantio direto na região do Cerrado Piauiens. Revista Brasileira de Ciencia do Solo, Viçosa, MG, v. 36, n. 5, p.1591-1600, 2012. Disponível em: https://doi.org/10.1590/S0100-06832012000500023. Acesso em: 23 fev. 2019.

SANTOS, F. C.; FILHO, M. R. A.; DE NOVAIS, R. F.; FERREIRA, G. B.; CARVALHO, M. C. S.; FILHO, J. L. Fontes, doses e formas de aplicação de fósforo para o algodoeiro no Cerrado da Bahia. Revista Ceres, Viçosa, MG, v. 59, n. 4, p.537-543, 2012. Disponível em: https://doi.org/10.1590/S0034-737X2012000400015. Acesso em: 15 abr. 2019.

SÃO PAULO (Estado). Secretaria de Agricultura e Abastecimento. Instituto de Economia Agrícola - IEA. Preços médios mensais pagos e recebidos pela agricultura em 2018. São Paulo, 2018. Disponível em: http://ciagri.iea.sp.gov.br. Acesso em: 12 dez. 2018.

SILVA, F. S. Manual de análises de solos, plantas e fertilizantes. 2. ed. Brasília, DF: Embrapa, 2011. 627 p.

SILVA, H. R. F.; AQUINO, L. A. DE; BATISTA, C. H. Residual effect of phosphate fertilizer on sunflower productivity in succession to cotton. Bioscience Journal, Darmstadt, v. 27, n. 5, p.786-793, 2011.

SOUSA, D. M. G.; LOBATO, E. Cerrado: correção do solo e adubação. 2. ed. Brasília, DF: Embrapa Informação Tecnológica, 2004. 416 p.

WANG, X. X. LIU, S.; ZHANG, S.; LI, H. MAIMAITIAILI, B., FENG, G.; RENGEL, Z. Localized ammonium and phosphorus fertilization can improve cotton lint yield by decreasing rhizosphere soil pH and salinity. Field Crops Research, Amsterdam, v. 217, n. 3, p.75-81, 2018. Disponível em: https://doi.org/10.1016/j.fcr.2017.12.011. Acesso em: 10 fev. 2019.

WANG, X.; SHEN, J.; LIAO, H. Acquisition or utilization, which is more critical for enhancing phosphorus efficiency in modern crops? Plant Science, Limerick, v. 179, n. 4, p.302-306, 2010. Disponível em: https://doi.org/10.1016/j.plantsci.2010.06.007. Acesso em: 23 fev. 2019. 